\title{
Increasing efficiency of Cupola Furnace of a Small Size Foundry: A case study
}

\author{
Mr. Sanjay Sharma, Mr. Saurabh Singh Chandrawat \\ Lecturer Mechanical Engineering, Govt. Polytechnic College, Chittorgarh (Raj.) India \\ HOD (Mech. Engg.) Mewar University, Chittorgarh (Raj.)
}

\begin{abstract}
In today's industrial scenario huge losses/wastage occur in the manufacturing shop floor and foundry industries. This waste is due to operators, maintenance personal, process, tooling problems and nonavailability of components in time etc. Other forms of waste includes idle machines, idle manpower, break down machine, rejected parts etc. are all examples of waste. The quality related waste are of significant importance as they matter the company in terms of time, material and the hard earned reputation of the company. There are also other invisible wastes like operating the machines below the rated speed, startup loss, break down of the machines and bottle necks in process. Zero oriented concepts such as zero tolerance for waste, defects, break down and zero accidents are becoming a pre-requisite in the manufacturing and assembly industry. In this situation, a revolutionary concept of TPM has been adopted in many industries across the world to address the above said problems.
\end{abstract}

Keywords-TPM (Total Productive Maintenance) DBC (Divided Blast Cupola) BOP (Best Operating Practices) CFR (Coke Feed Ratio) Seiri (Sort), Seiton (Tidiness), Seiso (Cleaning), Seiketsu (Standardisation), Shitsuke (Discipline).

\section{INTRODUCTION}

TPM stands for Total Productive Maintenance, or productive maintenance with total participation. First developed in Japan, TPM is a team-based preventive and productive maintenance, both abbreviated as 'PM', and involves every level and every function in the organisation, from top executives to the production floor operators.

Preventive Maintenance can be thought of as a kind of physical check-up and preventive medicine for equipment. Just as human life expectancy has been expanded by the progress in preventive medicine to prevent human suffering from disease, the plant equipment service life can be prolonged by preventing equipment failure (disease) beforehand. In 1971, Nippon Denso Co. introduced and successfully implemented a program called 'Total Productive Maintenance' in Japan. They won the PM Excellence Plan Award for their efforts. This was the beginning of TPM in Japan. It got popular rapidly in the U.S.

TPM describes a synergistic relationship among all organisational functions, but particularly between production and maintenance, for the continuous improvement of product quality, operational efficiency, capacity assurance and safety. Maintenance is a function in an organisation that operates in parallel with production. The primary output of production is the desired product and its secondary output is a demand for maintenance, which is in turn an input for the maintenance function. Maintenance results in a secondary input to production in the form of production capacity. While production manufactures the product, maintenance produces the capacity for production. Therefore, maintenance affects production by increasing production capacity and controlling the quality and quantity of output.

It can be considered as the medical science of machines. Total Productive Maintenance (TPM) is a maintenance program, which involves a newly defined concept for maintaining plants and equipment. The goal of the TPM program is to markedly increase production while, at the same time, increasing employee morale and job satisfaction.

TPM brings maintenance into focus as a necessary and vitally important part of the business. It is no longer regarded as a non-profit activity. Down time for maintenance is scheduled as a part of the manufacturing day and, in some cases, as an integral part of the manufacturing process. The goal is to hold emergency and unscheduled maintenance to a minimum.

\subsection{Objectives of TPM}

- Avoid wastage in a quickly changing economic environment. 
- Producing goods without reducing product quality.

- Reduce cost.

- Produce a low batch quantity at the earliest possible time.

- Goods send to the customers must be non-defective.

- A Safer Workplace

\subsection{TPM Targets}

- Obtain maximum OEE (Overall Equipment Effectiveness)

- Operate in a manner, so that there are no customer complaints.

- Reduce the manufacturing cost by $8-10 \%$.

- Achieve $100 \%$ success in delivering the goods as required by the customer.

- Maintain an accident free environment.

- Increase the suggestions from the workers/employees by 3 times.

\subsection{Pillars of TPM}

Because TPM involves everyone, the concept of TPM can be illustrated as being supported by seven TPM Activities "Pillars", all of which are supported by 5S.

\subsubsection{Pillar 1 - 5s:}

TPM starts with 5S. It is a systematic process of housekeeping to achieve a serene environment in the work place involving the employees with a commitment to sincerely implement and practice housekeeping. Problems cannot be clearly seen when the work place is unorganized. Cleaning and organizing the workplace helps the team to uncover problems. Making problems visible is the first step of improvement. $5 \mathrm{~S}$ is a foundation program before the implementation of TPM.

\section{S TERMS}

\begin{tabular}{|c|c|c|}
\hline Japanese Term & English Translation & Equivalent 'S' term \\
\hline Seiri & Organisation & Sort \\
\hline Seiton & Tidiness & Systematise \\
\hline Seiso & Cleaning & Sweep \\
\hline Seiketsu & Standardisation & Standardise \\
\hline Shitsuke & Discipline & Self - Discipline \\
\hline
\end{tabular}

\subsubsection{Pillar 2 - Jishu Hozen (Autonomous maintenance):}

This pillar is geared towards developing operators to be able to take care of small maintenance tasks, thus freeing up the skilled maintenance people to spend time on more value added activity and technical repairs. The operators are responsible for upkeep of their equipment to prevent it from deteriorating. By use of this pillar, the aim is to maintain the machine in new condition. The activities involved are very simple nature. This includes cleaning, lubricating, visual inspection, tightening of loosened bolts etc.

\subsubsection{Pillar 3 - Kaizen}

"Kai" means change, and "Zen" means good (for the better). Basically kaizen is for small improvements, but carried out on a continual basis and involve all people in the organization. Kaizen is opposite to big spectacular innovations. Kaizen requires no or little investment. The principle behind is that "a very large number of small improvements are move effective in an organizational environment than a few improvements of large value. This pillar is aimed at reducing losses in the workplace that affect our efficiencies. By using a detailed and thorough procedure we eliminate losses in a systematic method using various Kaizen tools. These activities are not limited to production areas and can be implemented in administrative areas as well.

\subsubsection{Pillar 4: Planned Maintenance}

It is aimed to have trouble free machines and equipment producing defect free products for total customer satisfaction. 


\subsubsection{Pillar 5: Quality maintenance}

It is aimed towards customer delight through highest quality through defect free manufacturing. Focus is on eliminating non-conformances in a systematic manner, much like Focused Improvement. We gain understanding of what parts of the equipment affect product quality and begin to eliminate current quality concerns, and then move to potential quality concerns. Transition is from reactive to proactive (Quality Control to Quality Assurance).

\subsubsection{Pillar 6: Education and training}

It is aimed to have multi-skilled revitalized employees whose morale is high and who has eager to come to work and perform all required functions effectively and independently. Education is given to operators to upgrade their skill. It is not sufficient know only "Know-How" by they should also learn "Know-why". By experience they gain, "Know-How" to overcome a problem and what is to be done. This they do without knowing the root cause of the problem and why they are doing so. Hence it become necessary to train them on knowing "Know-why". The employees should be trained to achieve the four phases of skill. The goal is to create a factory, full of experts.

\subsubsection{Pillar 7: Office TPM}

Office TPM should be started after activating four other pillars of TPM (JH, KK, QM, and PM). Office TPM must be followed to improve productivity, efficiency in the administrative functions to identify and eliminate losses. This includes analyzing processes and procedures towards increased office automation.

\subsubsection{Pillar 8: Safety, health and environment}

In this area focus is on to create a safe workplace and a surrounding area that is not damaged by our process or procedures. This pillar plays an active role in each of the other pillars on a regular basis.

\subsection{Introduction to Foundry Industry}

Energy is one of the important inputs in a foundry unit. It is used for melting iron in a cupola, and constitutes about $12 \%-15 \%$ of the total cost of production. Hence, optimal utilization of energy is vital for the profitability of a foundry's operations. However, a majority of small-scale foundries in India use outmoded, low-efficiency cupolas that in addition generate considerable quantities of greenhouse gases and particulate emissions.

There are about 6000 foundries in India; the majority of them are small scale units. These units produce high-value castings that are used in a variety of industrial activities, in India and abroad. Small-scale foundries also produce a vast range of low-value castings such as manhole covers, drainage pipes, and so on that forms a vital part of civic infrastructure. The small-scale foundry industry is a huge employment provider; an estimated half-a-million people find jobs as skilled, semi-skilled, or casual workers in grey iron foundry units. Most foundries depend on cupolas that operate with low energy efficiencies and generate high levels of greenhouse gases and particulate emissions. The foundry workforce faces diverse problems-harsh working conditions, health hazards, poor wages, and contract/bonded labour.

The foundry industry in particular is an industry where efficient production and environmental impacts are closely tied, so the implementation of TPM philosophies can have a powerful effect on a foundry's economic and environmental sustainability.

Proposed work is emphasized on waste minimization and value addition in every facet of the industry by applying TPM philosophy which leads to overall cost reduction

Proposed work is also emphasized on the minimization of emissions, efficient use of raw material and energy, optimum process chemical utilization, the recovering and recycling of waste and the substitution of harmful substances in considered foundry.

Foundry is one of the most energy intensive metallurgical industries. The major part (50\%) of the energy consumed in Foundry is in the melting units and it is the prime source of air pollution. Energy also contributes to the major cost input to the production of castings. Therefore, the cupola melting process is targeted for achieving the aforesaid goal of improving the energy efficiency of small scale foundry unit.

\subsection{Energy Audit}

In order to ascertain the causes and extent of inefficiency in energy use in foundry, the audits revealed that the CFR is 1: $4(25 \%)$ in a conventional cupola, This CFR compared poorly with the best levels achieved of about 1:10 (10\%). Thus, there is a large potential for improving furnace efficiency; specifically, to reduce coke consumption by proper design of the cupola and adoption of BOP (Best Operating Practices) as shown in figure below 

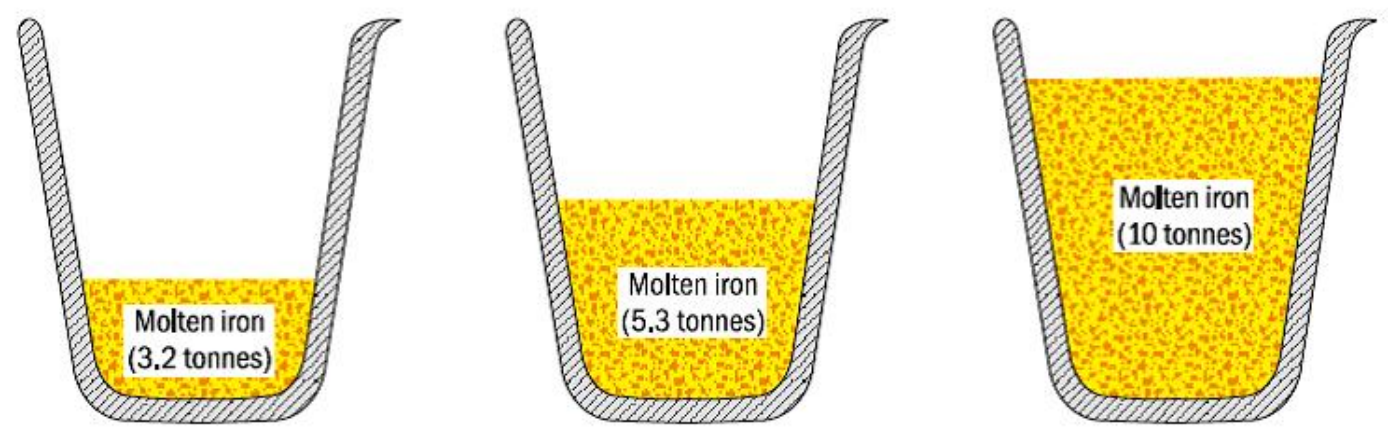

Amount of molten metal that can typically be produced, per tonne of coke, in Conventional cupola, Sub-optimal DBC, Optimal DBC with BOP
(a) Conventional cupola
(b) Sub-optimal DBC
(c) Optimal DBC with BOP

\subsection{Causes of Low Energy Efficiency}

- Poor furnace design.

- Poor operating practices.

- Non-uniform size of charge material.

\subsection{Energy Savings in Cupola}

Cupola, which is the most commonly used melting furnace, is also the most energy intensive operation. It accounts for up to $50 \%$ of a foundry's total energy consumption and is a prime candidate to focus attention on, for improving energy use efficiency in a foundry. The following operating practices are recommended for efficient cupola operation. Amongst many operating practices recommended for efficient cupola operations, we have chosen furnace lining where kaizen is being applied.

\subsubsection{Furnace lining}

Lining material, thickness and its sintering play important role in energy saving. Thick lining reduces furnace volume and hence the metal output resulting high specific energy consumption. Thin lining, though it improves the power density, promotes heat loss from the side wall. Lining material with high thermal conductivity causes more heat loss. Lining material with long sintering cycle time consumes much energy for the first heat to get ready. Improper lining causes premature failure. Therefore it is important to do lining as prescribed by the furnace manufacture to get optimum result for energy consumption. Use of pusher block to remove old lining in place of manual breaking contributes in reducing cycle time of lining hence overall specific energy per MT of liquid metal.

\subsection{Use of Tools like TPM, 5 'S' and Kaizen \\ 1.8.1 TPM}

Total productive maintenance has become very popular tool in reduction of breakdowns drastically. Out of 7 pillars of TPM, autonomous maintenance usually done by operator himself helps significantly in up keeping of equipments. It cannot be viewed by the employees as an option or "just another initiative." The involvement of every employee at every level of the organization is crucial. No level can be left out, especially middle management or floor supervisors. In the end it's the "people that make the difference" and make the organization function. Kaizen helps in following various processes sequentially.

\subsubsection{5 ' $S$ ' and safety}

$5 \mathrm{~S}$ is an acronym for activities which provide for an ordered workplace in which visual cues can facilitate problem detection and resolution. In English, the 5S's stand for Sort, Straighten, Shine, Standardize, and Sustain. Frequently Safety is included as a sixth ' $S$ ' because of its importance to the workers and to the community. Lean manufacturing principles ultimately target the elimination of all forms of waste. The 5S process follows the same philosophy and helps to identify what is waste so that it can be eliminated. A $5 \mathrm{~S}$ cornerstone is "the right thing in the right place at the right time." 5 ' $S$ ' helps in better housekeeping and safety at the working floor. A clean floor will quickly show a leak in a system, where material is being wasted. 


\subsubsection{Kaizen applied to furnace lining:}

It is studied that thick lining reduces furnace volume and hence the metal output resulting high specific energy consumption. Thin lining, though it improves the power density, promotes heat loss from the side wall. Lining material with high thermal conductivity causes more heat loss.

During lining work is done, it is observed that I S - 8 (high alumina) refractory bricks are lined with patch mortar containing alumina- silica mixture as shown in figure. The shape \& orientation of standard bricks provide 9 " lining thickness where as furnace manufacturer's recommendation for optimum results is 7.5 ". Easy availability of standard bricks (size 4.5" x 3" x 9") is found the reason behind such bad practice.

\section{All dimensions are in inches}

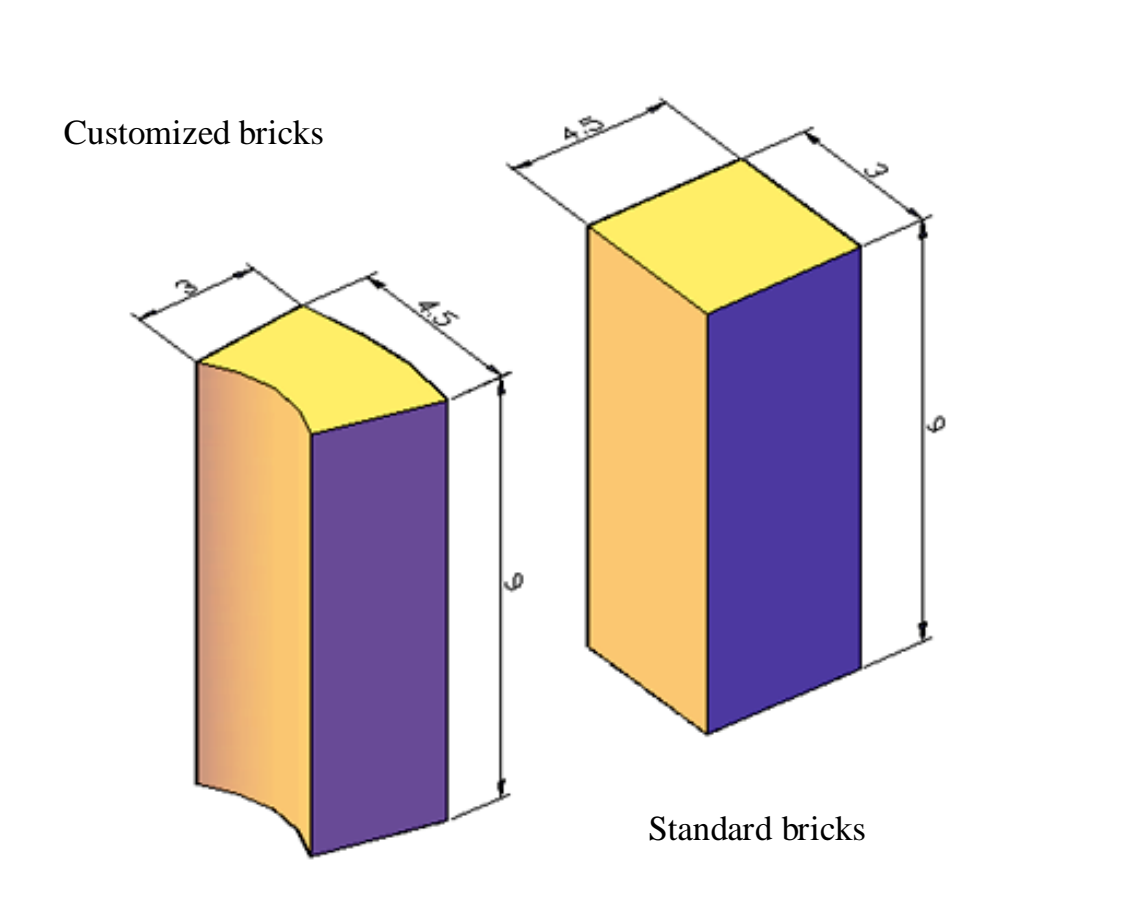

\section{Size \& Shape of customized and standard bricks}

Kaizen is applied; customized bricks as shown in figure are purchased which are manufactured on order. Next time when cupola will be lined with customized bricks, the shape \& layout of bricks will provide 7.5" lining thickness as shown in figure which will increase the furnace volume and hence the metal output resulting low specific energy consumption.

Before:

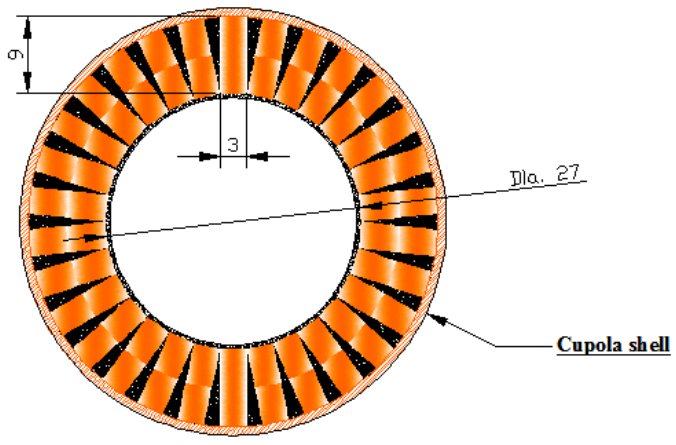

After:

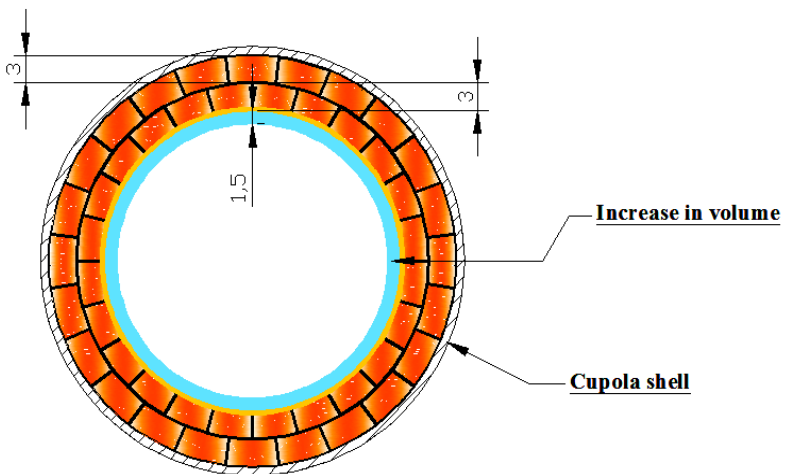

Layout of standard bricks

All Dimensions are in Inches.

Layout of customize bricks. 


\section{ANALYSIS}

Observations are taken for 12 hours cupola running. (Rate of Molten Metal per hr is 2.5 tonne.)

OBSERVATION SUMMARY

\begin{tabular}{|c|l|l|l|}
\hline S.No. & \multicolumn{1}{|c|}{ DESCRIPTION } & $\begin{array}{l}\text { PREVIOUS } \\
\text { OBSERVED } \\
\text { STATUS }\end{array}$ & $\begin{array}{l}\text { PRESENT } \\
\text { OBSERVED } \\
\text { STATUS }\end{array}$ \\
\hline 1. & Weight of molten metal & 30.00 Tonne & 31.05 Tonne \\
\hline 2. & Coke consumption & 7.5 Tonne & 6.21 Tonne \\
\hline 3. & Wastage & 2.25 Tonne & 1.863 Tonne \\
\hline 4. & $\begin{array}{l}\text { Cross sectional area of cupola which is } \\
\text { proportional to output melt. }\end{array}$ & 572.78 inch $^{2}$ & 707.14 inch $^{2}$ \\
\hline
\end{tabular}

\section{FORMULAE FOR CALCULATIONS}

Percentage CFR $=\left(\frac{\text { Molten metal }}{\text { Coke consumption }}\right) \times 100$

$\%$ Saving in coke $=\left(\frac{(\text { Previous coke consumption })-(\text { Present coke consumption })}{\text { Previous coke consumptionge }}\right) \times 100$

$$
\begin{aligned}
\text { Sp. Energy consumption } & =\left(\frac{\text { Coke consumption }}{\text { molten metal }}\right) \times 100 \\
\text { Percentage wastage } & =\left(\frac{\text { wastage }}{\text { molten metal }}\right) \times 100
\end{aligned}
$$

Percentage increase in output $=\left(\frac{(\text { Present area }- \text { Previous area })}{\text { Present area }}\right) \times 100$

\section{OUTCOME SUMMARY}

\begin{tabular}{|l|l|l|}
\hline S.No. & \multicolumn{1}{|c|}{ Description } & \multicolumn{1}{|c|}{ Outcome } \\
\hline 1. & Percentage CFR & $\begin{array}{l}\text { Previous Status = 25\% } \\
\text { Present Status = 20\% }\end{array}$ \\
\hline & Percentage Saving in coke & $17.2 \%$ \\
\hline & $\begin{array}{l}\text { Sp. Energy consumption (SEC) } \\
\text { In Tonne coke / Tonne of melt }\end{array}$ & $\begin{array}{l}\text { Previous Status }=0.25 \\
\text { Present Status }=0.20\end{array}$ \\
\hline & $\begin{array}{l}\text { Percentage wastage } \\
\text { Percentage increase in output due to } \\
\text { increase in cross sectional area of cupola }\end{array}$ & $\begin{array}{l}\text { Previous Status = 7.5\% (approx.8\%) } \\
\text { Present Status }=6 \%\end{array}$ \\
\hline
\end{tabular}

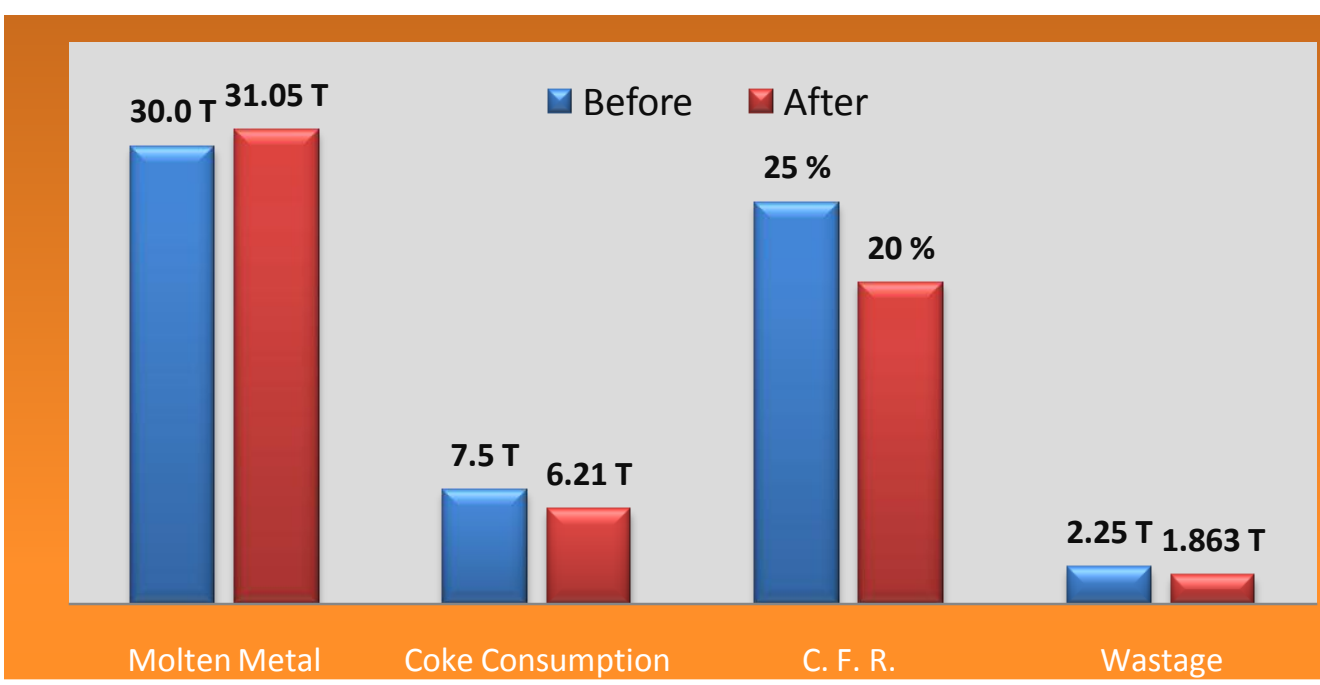

Result comparison on the basis of 12 Hrs. furnace running 


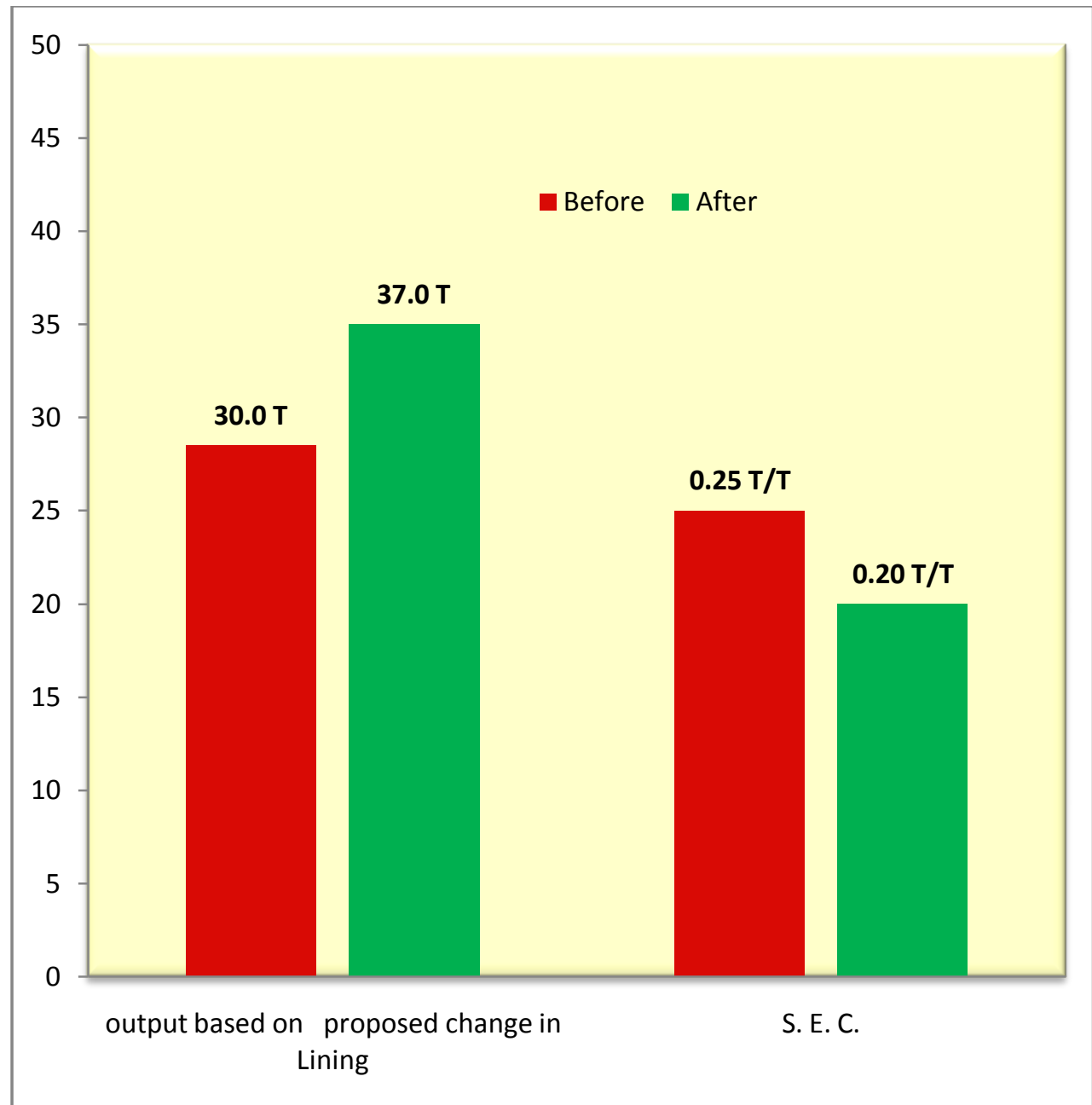

\section{Result comparison on the basis of 12 Hrs. furnace running}

\section{Thus above charts show that :}

1. Coke feed ratio gets improved from 1: 4 to 1:5 which results $17.19 \%$ saving in coke consumption.

2. Wastage is reduced from $7.5 \%$ to $6 \%$.

3. Kaizen not only produces direct impact on productivity, quality and safety, it extends indirect benefits also. Working conditions are improved by improvement through Kaizen.

4. Kaizen applied to furnace lining increased the furnace volume and hence the metal output by about $19 \%$ resulting in low specific energy consumption.

\section{CONCLUSION}

Significant energy savings and environment protection are realized in the foundry by applying various energy saving measures, adopting Best Operating Practices and implementing simple housekeeping measures. In general, adoption of the following measures resulted in higher energy efficiency, lower operating costs and increased profit and equipment life.

\section{ACKNOWLEDGEMENT:}

I would like begin my acknowledgements by thanking Mr O P Sharma, President \& Owner and his team, who supported me throughout my project with his patience and knowledge whilst allowing me the room to work in my own way.

First and foremost I offer my sincerest gratitude to my M. Tech. Guide, Mr. Saurabh Singh Chandrawat Head of Mechanical Engineering Department, Mewar University, Chittorgarh (Rajasthan) for guiding me in the project whenever I was in difficulty and were always ready with positive solution. My special thanks to Mr. Dhwajkirti Sharma Dy. Dean who was always inspirational to me from the start of my project. Also my thanks to whole of the teaching staff of Mech. Deptt. of Mewar University especially Manvendra Sir who enriched my knowledge during whole project. Last but not the least, Sh. J.P.Pidva, my guru and mentor who was my inspiration right from the word go. 


\section{REFERENCES}

[1] Kathleen E. McKone, Roger G. Schroeder and Kristy O. Cua, "Total productive maintenance: a contextual view", journal of operation management, vol. 17, pp. 123-144, 1999.

[2] Jhon Roup Vice President HSB Reliability Technologies, Alexandria, VA, "Moving beyond TPM to total plant reliability: Redefining the concept to optimize benefits", Plant engineering, 53, 2, Pro Quest Science Journals, Feb 1999.

[3] G. Chand and B. Shirvani, "Implementation of TPM in cellular manufacture", journal of material processing technology, vol. 103, pp. 149-154, 2000.

[4] I. B. Hipkin and C. De Cock, "TQM and BPR: lessons for maintenance management", International journal of management science, vol. 28, pp. 277-292, 2000.

[5] Kathleen E. McKone, Roger G. Schroeder and Kristy O. Cua, "The impact of total preventive maintenance practices on manufacturing performance", journal of operations management, vol. 19, pp. 39-58, 2001.

[6] Kristy O. Cua, Kathleen E. McKone and Roger G. Schroeder, "Relationship between implementation of TQM, JIT and TPM and manufacturing performance", journal of operations management, vol. 19, pp. 675-694, 2001.

[7] F.K. Wang and W. Lee, "Learning curve analysis in total productive maintenance", International journal of management science, vol. 29, pp. 491-499, 2001.

[8] Erbe Heinz-H., "Low cost intelligent automation in manufacturing", $15^{\text {th }}$ Triennil world congress, Barcelona, Spain, 2002.

[9] Hongyi Sun, Richard Yam and Ng Wai-Keung, "The implementation and evaluation of total productive maintenance (TPM) - an action case study in a Hong Kong manufacturing company”, international journal of advance manufacturing technology, vol. 22, pp. 224-228, 2003.

[10] M. C. Eti, S. O. T. Ogaji and S. D. Probert, "Implementing total productive maintenance in Nigerian manufacturing industries", Applied energy, vol. 79, pp. 385-401, 2004. 